\title{
REPRESENTANTES DA IMPRENSA RIO-GRANDENSE NO PERÍODO REGENCIAL: \\ O CONTINENTINO E O RECOPILADOR LIBERAL
}

Christiane Pereira ${ }^{1 ; 2}$

\section{Resumo}

Utilizando a imprensa como fonte de pesquisa, buscamos analisar parte da dinâmica dos debates políticos de Porto Alegre no período regencial a partir das publicações d'O Continentino e d'O Recopilador Liberal. Cada periódico defendia e discutia os projetos políticos propostos pelos grupos de moderados, exaltados e caramurus na recente imprensa do Rio Grande do Sul, projetos esses que já eram divulgados e defendidos pela imprensa de todo o Brasil em proporções bem maiores.

\section{Palavras-chave}

Imprensa - Rio Grande do Sul - projetos políticos.

\section{REPRESENTATIVES OF THE RIO-GRANDENSE PRESS IN THE REGIONAL PERIOD: O CONTINENTINO AND O RECOPILADOR LIBERAL}

\section{Summary}

Using the press as a source of research, we sought to analyze part of the dynamics of the political debates of Porto Alegre in the Regency period, from the publications of $O$ Continentino and O Recopilador Liberal. Each newspaper defended and discussed the political projects proposed by the groups of moderados, exaltados and caramurus in the recent press in Rio Grande do Sul, which projects were already publicized and defended by the press in all of Brazil in much larger proportions.

\section{Keywords}

Press - Rio Grande do Sul - political projects.

\footnotetext{
${ }^{1}$ Universidade Federal Rural do Rio de Janeiro (UFRRJ). Rio de Janeiro - Rio de Janeiro - Brasil.

${ }^{2}$ Licenciada e Mestre em História pela Universidade Federal Rural do Rio de Janeiro. Doutoranda pelo Programa de Pós-

Graduação em História da Universidade Federal Rural do Rio de Janeiro. E-mail:chrisppereira@gmail.com.
} 


\section{Introdução}

Sendo presumível a força da imprensa como meio de comunicação com maior alcance pelo menos desde o século XVII na Europa e século XIX no Brasil é ela a fonte principal para o desenvolvimento deste trabalho. Tendo como objetivo desvendar características da cultura impressa do Rio Grande do Sul, elegemos dois jornais de posições políticas opostas, O Continentino e O Recopilador Liberal, no período em que ambos estavam em circulação: 1832 e 1833.

Segundo Tania Regina de Luca, poucos trabalhos até a década de 1970 se valiam de "jornais e revistas como fonte para o conhecimento da história no Brasil" 3 . Considerando dois trabalhos de peso anteriores à década de 1970, de Hélio Vianna, omitido pela autora, e Nelson Werneck Sodré sobre a história da imprensa, os periódicos passaram a ser utilizados como instrumentos de pesquisa e a serem reconhecidos como fonte importante no último quartel do século XX.

A utilização da imprensa para a confirmação de fatos, aspectos sociais, políticos ou econômicos, bem como dados estatísticos ou demográficos deu a esta fonte grande espaço como instrumento valioso de pesquisa. É o que Tania de Luca chama de escrita da história “por meio da imprensa". Para esta autora, o reconhecimento da imprensa se deu com a renovação dos temas, das problemáticas e dos procedimentos metodológicos que a terceira geração dos Annales propôs em 1972. Este contexto histórico fez emergir a necessidade de se buscar novos objetos e abordagens. A virada linguística e sua discussão em torno das narrativas e a demanda de estudos sobre os movimentos sociais abriram espaço para os periódicos e suas informações. Entretanto, o uso de jornais como instrumentos de pesquisa recebeu críticas e observações como a de José Honório Rodrigues em 1968 acerca da imparcialidade e tendenciosidade dos periódicos ${ }^{4}$. O que de fato devemos entender é que a fonte impressa, assim como qualquer outra fonte escrita, pode ou não ser fidedigna, e compreender, como sugere Tania de Luca, que nos bastidores da produção impressa é que encontraremos as "motivações que levaram à decisão de dar publicidade a alguma coisa"s.

Apoiando-se nas mudanças dos temas, abordagens e problemáticas, principalmente na história política dos anos de 1960 e 1970 em diante, a apresentação da obra 200 anos de imprensa no Brasil das organizadoras Silvia Carla Fonseca e Maria Letícia Corrêa, contém grande apanhado dos autores que vêm trabalhando com a imprensa desde então. É importante perceber nesta obra a "evolução" na utilização dos impressos - desde a história da imprensa (o surgimento dos jornais e pasquins, das tipografias, os redatores, os livros), os assuntos relacionados (o estudo dos vocabulários políticos, os espaços públicos, as práticas de leitura, as bibliotecas), até a reflexão sobre conceitos.

Se, por um lado, a década de 1970 representa um momento fortuito para a valorização da imprensa como fonte e objeto de estudos historiográficos, a década de 1990, segundo Silvia Fonseca e Maria Letícia Corrêa, é um momento de domínio e sofisticação da história dos impressos no Brasil com maior "aprofundamento e delimitação dos objetos de pesquisa" . No que concerne ao século XIX, as autoras apontam para as obras dedicadas ao período da Independência, Primeiro Reinado e regências que contribuíram bastante para a diversificação dos campos de análise sobre o Império do Brasil.

Diante desta proliferação de estudos utilizando a imprensa ora como objeto, ora como fonte, as perspectivas inauguradas com as novas abordagens historiográficas das últimas três décadas deixaram de lado a utilização da imprensa como detentora dos fatos ou determinante dos acontecimentos para dar a ela papel fundamental para entendermos contextos históricos e, principalmente, enriquecer pesquisas de história política, cultural e social.

\footnotetext{
${ }^{3}$ LUCA, Tania Regina de. História dos, nos e por meio dos periódicos. In: PINSKY, Carla (org.). Fontes históricas. $2^{\text {a }}$ ed. São Paulo: Contexto, 2006.

${ }^{4}$ RODRIGUES, José Honório. Teoria da história do Brasil: introdução metodológica. $3^{\text {a }}$ ed. rev. São Paulo: Companhia Editora Nacional, 1968. LUCA, Tania Regina de. História dos, nos e por meio dos periódicos. In: PINSKY, Carla (org.). Fontes históricas. $2^{\text {a }}$ ed. São Paulo: Contexto, 2006, p. 115 e 116.

${ }_{5}^{5}$ LUCA, Tania Regina de. História dos... Op. cit, p. 140.

${ }^{6}$ FONSECA, Silvia Carla Pereira de Brito; CORREAA, Maria Letícia (orgs.). 200 anos de imprensa no Brasil. Rio de Janeiro: Contra Capa, 2009.

${ }_{7}$ Idem. p. 11.
} 


\section{O desenvolvimento da imprensa e o Rio Grande do Sul}

Para François-Xavier Guerra, a análise de lugares e formas de organização fornece informações importantes para a compreensão das novas práticas políticas, portanto, da construção e difusão da modernidade ${ }^{8}$.

O início do século XIX representa a valorização do discurso escrito no Brasil, quando as discussões políticas saíram dos círculos "palacianos” para ocupar os novos espaços públicos. Esses espaços são entendidos aqui como lugares de manifestações e de novas práticas políticas fora do domínio das autoridades, como aponta Marco Morel: "pontos de sociabilidades mais ou menos informais como os locais de venda da imprensa, livrarias, boticas e cafés", as ruas como "locus privilegiado de se fazer política" . Para o autor, novas tipografias também significavam novos espaços de sociabilidade, bem como a produção de panfletos significou o maior alcance de público.

Tendo como premissa que as duas primeiras tipografias foram criadas na Bahia e no Rio de Janeiro, vale ressaltar a importância dessas duas províncias como principais redutos dessa nova prática cultural no Brasil: a imprensa. O primeiro jornal oficial produzido no Brasil foi a Gazeta do Rio de Janeiro publicada em 10 de setembro de 1808. Na Bahia, a tipografia da Viúva Serva \& Carvalho, antiga Silva Serva, surgiu em 1811 e publicou o jornal áulico Idade d'Ouro do Brasil a partir de maio de 1811.

Como reflexo da Revolução do Porto, a profusão de ideias liberais na década de 1820 no Brasil se deu, principalmente, via imprensa. Os panfletos, manuscritos e impressos foram muito eficazes na promoção dos debates e garantiram amplo alcance, tema da obra Às armas cidadãos, trabalho recente sobre os panfletos da Independência ${ }^{10}$. Sobre o período de 1820 a 1823, os autores da obra reuniram os panfletos publicados na Bahia, no Rio de Janeiro e no Porto, reiterando a importância dessas duas províncias brasileiras para o desenvolvimento da imprensa deste lado do Atlântico. Novas oficinas surgiram no Rio de Janeiro e no Maranhão. Myriam Pires, ao analisar a Tipografia do Diário em sua dissertação de mestrado, também fez um panorama dos espaços de criação da imprensa mostrando a dificuldade de produzir dados estatísticos concretos sobre as tipografias. A autora cita alguns trabalhos que contabilizam as tipografias particulares como o de Lúcia Neves, em Corcundas e constitucionais, que identificou cinco tipografias na Corte entre 1821 e 1822: a de Moreira e Garcez, do Diário, de Silva Porto; o da Oficina dos Annaes Fluminenses e o de Torres e Costa; o de Moreira de Azevedo que identificou nove no período de 1821 e 1829; e o de Paulo Berger que contabilizou 13 entre 1821 e $1831^{11}$.

As províncias da Bahia, Rio de Janeiro, Maranhão, Minas Gerais, Ceará, São Paulo, Pará e Pernambuco já publicavam jornais de cunho oficial e partidário, ou seja, propagadores dos projetos e ideias das facções políticas. Diferentemente do que aconteceu com a imprensa nessas províncias, o Rio Grande do Sul só publicou o seu primeiro jornal em $1827^{12}$. O surgimento da imprensa nesta província se deu no governo do presidente Salvador José Maciel ${ }^{13}$, com a criação do Diário de Porto Alegre, jornal de cunho oficial, que publicava atos do governo e da administração ${ }^{14}$. Com a criação deste periódico,

\footnotetext{
8 GUERRA, François-Xavier. Modernidad e independencias. Madri: Mapfre, 1992. p. 87-88.

${ }^{9}$ MOREL, Marco. As transformações dos espaços públicos: imprensa, atores políticos e sociabilidades na cidade imperial (1820-1840). São Paulo: Hucitec, 2005. p. 161-165.

${ }^{10}$ CARVALHO, José Murilo de; BASTOS, Lúcia; BASILE, Marcello (org.). Às armas, cidadãos! Panfletos manuscritos da Independência do Brasil (1820-1823). São Paulo: Companhia das Letras; Belo Horizonte: Editora UFMG, 2012.

${ }^{11}$ PIRES, Myriam. Impressão, sociabilidades e poder: três faces da Tipografia do Diário na Corte do Rio de Janeiro (1821-1831). Dissertação (Mestrado), Universidade do Estado do Rio de Janeiro, Rio de Janeiro, 2008, cap. III, p. 115-116. Esta autora também chama atenção para a identificação de 19 tipografias no período de 1821-1822, em trabalho de 2004 de MOREL Marco; CARVALHO, Fernanda Costa; PIRES Myriam. História da imprensa no Brasil império: abordagem metodológica e síntese histórica (1822-1849). Rio de Janeiro: Universidade do Estado do Rio de Janeiro, 2004 (trabalho de iniciação científica). Para os trabalhos citados ver NEVES, Lúcia Maria Bastos Pereira das. Corcundas e constitucionais: a cultura política da Independência (1820-1822). Rio de Janeiro: Revan / Faperj, 2003; AZEVEDO, Manuel Duarte Moreira de. Origem e desenvolvimento da imprensa no Rio de Janeiro. Revista Trimestral do Instituto Histórico Geográfico e Etnográfico Brasileiro, Rio de Janeiro, t. XXVIII, 1865; BERGER, Paulo. A tipografia no Rio de Janeiro (1808-1900). Rio de Janeiro: Companhia Indústria Nacional de Papel Pirahy, 1984.
}

12 Na província de Goiás, o primeiro jornal surgiu apenas em 1830.

${ }^{13}$ Salvador Maciel constituiu carreira militar, ocupando o cargo de inspetor e depois intendente do Arsenal do Exército. Foi ministro da Marinha de 5 de fevereiro de 1836 a 16 de maio de 1837, chegou à patente de brigadeiro e, entre 1840 a 1846 , foi diretor da Escola Militar da Corte.

${ }^{14}$ STRELOW, Aline. Primórdios da imprensa literária no Rio Grande do Sul: a história do jornal O Guayba. Intercom, Rev. Bras. Ciênc. Comum. [online], v.39, n.2, p-19-36, 2016. 
Maciel inaugurou uma nova fase naquela província. $\mathrm{O}$ marechal de campo, enquanto presidente da província do Rio Grande, enfrentou diversos desafios devido ao estado de guerra que permaneceu por todo o tempo do seu governo. Preocupou-se com a desorganização militar da província, mas também colocou em prática uma cultura que já se consolidava por muitas regiões do Brasil.

Poucos trabalhos dedicam-se à imprensa gaúcha na primeira metade do XIX. O foco de análise, na maioria das vezes, é a imprensa rio-grandense como um todo, ou casos específicos como os anos da Revolução Farroupilha ou mesmo a história de um jornal ${ }^{15}$. No que concerne a este trabalho, como dito anteriormente, reunimos dois jornais do período regencial antes da Revolução Farroupilha para contemplar esta imprensa recém-criada e tão incendiária, observando as diferenças de posicionamento entre eles. Os jornais escolhidos foram $O$ Continentino e O Recopilador Liberal que circularam nos anos subsequentes à abdicação. O período selecionado de análise foram os anos de 1832 e 1833 que compreendem a publicação de ambos os jornais concomitantemente. O objetivo principal é perceber a linguagem de cada periódico mediante sua postura partidária, ou seja, seus posicionamentos políticos.

Por informações do inventário disponível no site do Museu da Comunicação Hipólito José da Costa, no Rio Grande do Sul circularam 20 jornais no período regencial. Já nos registros de Nelson Werneck Sodré, constam mais 14 jornais além da lista do inventário citado acima ${ }^{16}$. Cruzando essas informações com a lista disponível no site do Instituto Histórico e Geográfico do Rio Grande do Sul, podemos acrescentar mais dois jornais. Portanto, contabilizamos cerca de 36 jornais circulando na província rio-grandense no período regencial. Um número razoável, mas muito diferente do Rio de Janeiro que, no mesmo período, contabiliza 215 jornais, segundo Marcello Basile ${ }^{17}$. Na análise deste autor, a vacância do trono, a extensão da esfera pública, o contexto de divergências políticas com a atuação de três grupos - moderados, exaltados e caramurus - contribuíram para a expansão da imprensa no Rio de Janeiro que contabilizou, nos três primeiros anos, 50\% das publicações de todo o período regencial ${ }^{18}$.

\footnotetext{
${ }_{15}^{15}$ Para trabalhos sobre a imprensa gaúcha ver: ALVES, Francisco das Neves. O periodismo gaúcho no século XIX: breves impressões históricas. Biblos, Rio Grande, vol. 23, n. 2, p. 137-166, 2009; BARRETO, Abeillard. Primórdios da imprensa no Rio Grande do Sul. Comissão Executiva do Sesquicentenário da Revolução Farroupilha. Porto Alegre, 1986; JUNG, Roberto Rossi. A gaúcha Maria Josefa, primeira jornalista brasileira. Porto Alegre: Martins Livreiro, 2004; REVERBEL, Carlos. Evolução da imprensa rio-grandense (1827-1845). In: Enciclopédia Rio-Grandense. Porto Alegre, 1956; RÜDIGER, Francisco. Tendências do jornalismo. Porto Alegre: Edipucrs, 2002; STRELOW, Aline. Primórdios da imprensa literária no Rio Grande do Sul... Op. Cit., 2016.

16 SODRÉ, Nelson Werneck. A história da imprensa no Brasil. Rio de Janeiro: Mauad, 1999. p. 130-131.

${ }^{17}$ BASILE, Marcello. Inventário analítico da imprensa periódica do Rio de Janeiro na Regência: perfil dos jornais e dados estatísticos. In: CARVALHO, José Murilo de; NEVES, Lúcia Maria Bastos P. (org.). Dimensões e fronteiras do Estado brasileiro nos Oitocentos. Rio de Janeiro: Eduerj, 2014. p. 42.

${ }^{18}$ Ibidem, p. 43 e 44. Para a atuação dos grupos políticos moderados, exaltados e caramurus ver: BASILE, Marcello. O Império em construção: projetos de Brasil e ação política na Corte regencial. Tese (Doutorado), I.F.C.S., Universidade Federal do Rio de Janeiro, Rio de Janeiro, 2004.
} 
No gráfico abaixo consta a quantidade de publicações em circulação em cada ano do período regencial até o fim da Revolução Farroupilha ${ }^{19}$ na província do Rio Grande do Sul:

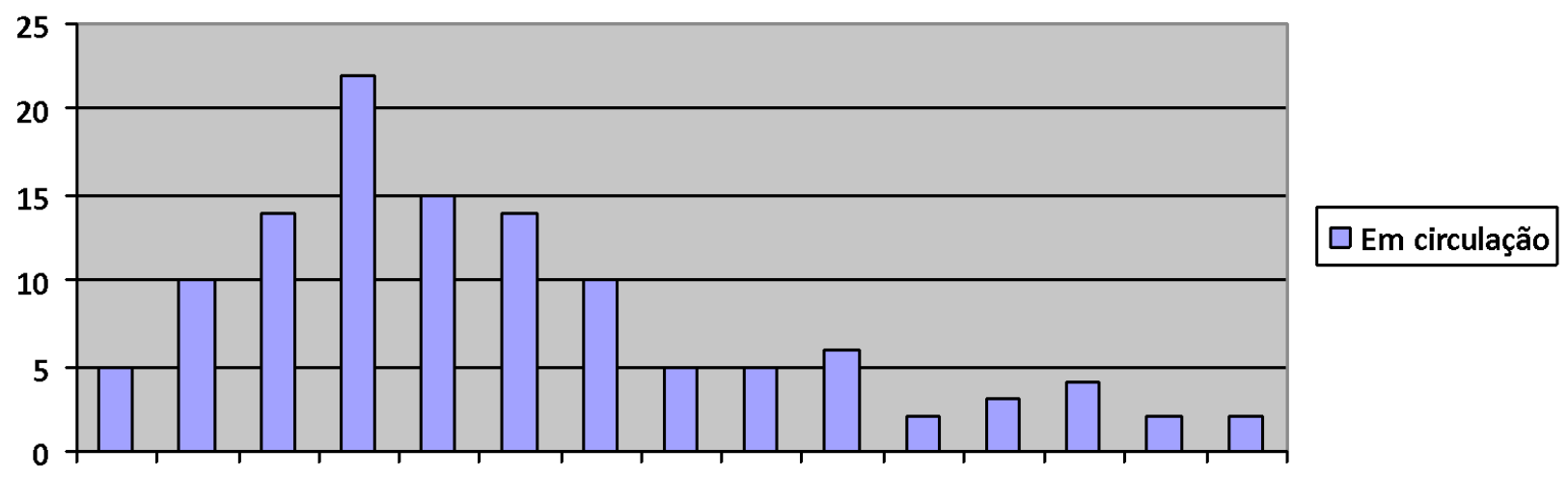

183118321833183418351836183718381839184018411842184318441845

Segundo Francisco das Neves Alves, a imprensa da província durante os anos regenciais era partidária e de enfrentamento. Durante a Revolução Farroupilha, a circulação dos jornais foi bastante prejudicada, principalmente depois de 1840 , como podemos observar no gráfico acima ${ }^{20}$. Na relação dos jornais do Rio Grande do Sul de Nelson Werneck Sodré, constam apenas dois jornais publicados nos anos de 1840: O Americano (setembro de 1842 a março de 1843) e Estrela do Sul (1843), mas encontramos também $O$ Analista (1840). Após a Farroupilha, segundo Alves, os pasquins preencheram os espaços públicos e progressivamente a imprensa foi se diversificando ${ }^{21}$. Já a imprensa literária desenvolveu-se na segunda metade do século XIX.

\section{A imprensa partidária: governistas $\mathrm{x}$ republicanos e/ou moderados $\mathrm{x}$ exaltados}

As crises política e econômica do final do Primeiro Reinado fortaleceram ainda mais os projetos liberais que vinham, desde a reabertura do Parlamento em 1826 e o revigoramento da imprensa periódica, ganhando vez no panorama político brasileiro. Duas facções políticas constituíram as principais linhas de oposição ao governo e de questionamento da Carta Constitucional: os exaltados e os moderados. A facção liberal moderada, criada em 1826, defendia, entre outros princípios, a soberania da nação, a centralização do poder, optando pelo justo meio (princípio originalmente aristotélico) entre o absolutismo e a democracia. Criada em 1829, a facção exaltada, adepta de um liberalismo radical, defendia a igualdade social, a república, o federalismo e a revolução como expressão de luta pela causa pública ${ }^{22}$. As facções utilizaram a imprensa para divulgar seus projetos publicando diversos jornais, além de formar redes de sociabilidade, como as sociedades. Moderados e exaltados atacavam o imperador por considerar que, sendo ele português, beneficiava seus conterrâneos na distribuição de cargos públicos, podendo lhes dar maiores regalias que aos brasileiros.

Outro grupo que compunha a cena política, atuante na imprensa, nos espaços de sociabilidade, bem como nas instituições governamentais durante o Primeiro Reinado, foi a facção áulica. Este grupo defendia o imperador e a Constituição de 1824, tendo uma participação significativa na imprensa da Corte no período posterior à outorga da Constituição até a abdicação do imperador em 1831. Já

\footnotetext{
${ }^{19}$ Vale ressaltar que, neste gráfico, informamos a quantidade de jornais em circulação em cada ano, sem especificar os jornais que foram criados e/ou encerraram suas publicações nos ditos anos.

${ }^{20} \mathrm{Na}$ relação dos jornais do Rio Grande do Sul de Nelson Werneck Sodré, constam apenas dois jornais publicados depois de 1840: O Americano (setembro de 1842 a março de 1843) e Estrela do Sul (1843), mas outros jornais foram publicados neste período no Rio Grande do Sul. O Analista, por exemplo, foi publicado em 1840, mas apenas dois números estão disponíveis para pesquisa no site da Biblioteca Nacional e datados erroneamente (1810 ao invés de 1840).

${ }^{21}$ ALVES, Francisco das Neves. O periodismo gaúcho no século XIX: breves impressões históricas. In: Biblos, Rio Grande, vol. 23, n. 2, p. 137-166, 2009.

22 BASILE, Marcello. Projetos de Brasil e construção nacional na imprensa fluminense (1831-1835). In: NEVES, Lúcia Maria Bastos; MOREL, Marco; FERREIRA, Tania Maria Bessone (org.). História e imprensa. Representações culturais e práticas de poder. Rio de Janeiro: DP\&A / Faperj, 2006.
} 
para o período posterior, exaltados, moderados e a facção caramuru, criada em 1832 para a defesa da Constituição e a recusa de qualquer reforma constitucional, formaram o conturbado contexto regencial.

Para entender os debates na imprensa no Rio Grande do Sul, os dois jornais selecionados para esta análise representam posicionamentos políticos opostos. Ambos foram publicados em Porto Alegre e circularam após a abdicação de d. Pedro I. O Continentino, jornal com tendências moderadas, iniciou sua publicação em $1831^{23}$ e finalizou em 1833. Já o republicano O Recopilador Liberal começou a circular em 1832 e terminou em 1836, sendo periódico oficial dos farrapos. Para analisar esses dois periódicos utilizamos os números disponíveis na Biblioteca Nacional: números 62 e 63 d'O Continentino, publicados em maio de 1832, mais 21 edições publicadas em 1833; e números 37 e 38 d'O Recopilador Liberal, publicados em outubro de 1832, mais 13 edições publicadas em 1833. A escolha desses jornais tem como premissa sua importância na esfera pública ${ }^{24}$ da capital da província, bem como seus enfrentamentos, como veremos a seguir.

O jornal $O$ Continentino, no ano de 1832, foi redigido inicialmente na Tipografia de Claude Dubreuil \& Cia, depois na Tipografia do Continentino, rua da Igreja, $n^{\circ} 67$, que se mudou para a rua Bragança, $\mathrm{n}^{\circ}$ 62. A epígrafe utilizada era a seguinte: "Le seul bien de l'Etat fait son ambition. Il hait la Tyrannie, et la Rebellion". Volt. Henr. C. 4. Já os números disponíveis para o ano de 1833 foram publicados pela Tipografia de Fonseca \& Companhia, na rua da Bragança, $\mathrm{n}^{\circ} 58$ e tinham como epígrafe uma frase do filósofo chinês Confúcio: "Quando se tractar da Salvação da Patria, não consultai, exponde a vida”. Segundo dados do Instituto Histórico e Geográfico do Rio Grande do Sul, este jornal estava ligado à Sociedade Maçônica dos Continentinos ${ }^{25}$. O jornal era publicado em quatro páginas e circulava duas vezes por semana; sua assinatura custava $2 \$ 000$ por trimestre e o número avulso, 80 réis. A publicação deste periódico pode ser dividida em duas fases: a primeira com a edição de João Manuel de Lima e Silva e Tito Livio Zambecari, de 27 de outubro de 1831 até 31 de dezembro se 1832, totalizando 130 números, dos quais apenas dois estão disponíveis para pesquisa; e a segunda com o redator Joaquim José de Araújo, de 3 de janeiro de 1833 a 27 de junho de 1833, totalizando 51 números, dos quais apenas 21 edições estão disponíveis para análise ${ }^{26}$. O Continentino da primeira fase é considerado por Sodré como um jornal moderado ${ }^{27}$. Na segunda fase, quando o jornal passou a ser redigido por Araújo, manteve a postura de defesa das instituições e das leis, mas, criticando o excesso de reformas e a criação de novas instituições, aproximou-se de um conservadorismo característico da facção caramuru. O redator do Continentino também redigia $O$ Inflexível, um jornal caramuru ${ }^{28}$ criado em 1832, publicado também em Porto Alegre.

Já o jornal O Recopilador Liberal foi publicado em 1832 pela Tipografia de V. F. de Andrade, na rua da Igreja, $n^{\circ} 36$ que, no ano seguinte, mudou-se para rua da Ponte. A epígrafe utilizada era uma frase atribuída ao abade Raynal: "A vil ambição do mando presta auxílio à tirania, se deixa escravizar para dominar, entrega os Povos para participar dos seus desejos, e renuncia a honra para obter dignidades, e títulos". O jornal também era publicado em quatro páginas e circulava duas vezes por semana, às quartas-feiras e sábados. Os redatores atribuídos à edição deste jornal são: Tito Lívio Zambecari, natural de Bolonha ${ }^{29}$, o uruguaio Manuel Ruedas ${ }^{30}$ e o militar José de Paiva Magalhães Calvet ${ }^{31}$.

\footnotetext{
${ }^{23}$ Tanto no inventário disponível online do Museu Hipólito José da Costa quanto nos dados retirados da obra de SODRÉ, Nelson Werneck. História da imprensa no Brasil. Op. Cit., consta esta data para o início da publicação d'O Continentino.

${ }^{24}$ Entendemos por "esfera pública" o conceito de Habermas: um espaço intermediário entre a sociedade civil e o Estado. Ver: HABERMAS, Jurgen, Mudança estrutural da esfera pública: investigações quanto a uma categoria da sociedade burguesa. Rio de Janeiro: Tempo Brasileiro, 1984.

25 Disponível em: https://www.ihgrgs.org.br/hemeroteca/cd_jornais_poa/CD/Continentino/continentino.htm.

${ }^{26}$ A pesquisa foi realizada a partir dos números dos dois jornais disponíveis na página eletrônica da Biblioteca Nacional Digital: $\leq$ http://bndigital.bn.gov.br/hemeroteca-digital/>.

27 SODRÉ, Nelson Werneck. A história..., p. 130.

${ }^{28}$ Idem. Ver também: COLLOR, Lindolfo. Garibaldi e a Guerra dos Farrapos. Brasília: Senado Federal, Conselho Editorial, 2016. p. 94.

${ }^{29}$ Tito Lívio Zambecari fez-se carbonário ainda em Bolonha, quando entrou em contato com sociedades secretas. Saiu fugido da Europa e se abrigou na América. Ao se estabelecer em Porto Alegre logo se aproximou dos liberais, prestando serviço de orientação de movimentos dos revolucionários, dos farrapos. Informações retiradas de: COLLOR, Lindolfo. Garibaldie a Guerra... Op. Cit., p. $92-94$.

${ }^{30}$ Manuel Eustáquio Ruedas era comerciante e teria aparecido em Porto Alegre em 1829. Natural da banda oriental, ele teria se naturalizado brasileiro. Ver: SCHMITT, Ânderson Marcelo. "Não admito escusa alguma": confiscos e recrutamentos na guerra civil rio-grandense (1835-1845). Dissertação (Mestrado), Universidade de Passo Fundo, 2014. p. 75.

${ }^{31}$ Calvet era natural de Porto Alegre e descendente de franceses. Ingressou na Escola de Marinha do Rio de Janeiro em 1824 . Veio dossiê Regência e Imprensa
} 
A estrutura de ambos os periódicos era muito parecida, desde o número de páginas até a organização das matérias. Nos dois podemos observar a primeira sessão intitulada "Interior", onde os redatores expunham notícias importantes do governo central, reproduzindo ofícios vindos do Rio de Janeiro, e também questões de interesse geral, esclarecendo assuntos relacionados à política nacional. Esta primeira sessão podia ocupar metade do jornal. Em seguida, uma sessão sobre assuntos locais intitulada "Porto Alegre", mas que não aparece em todos os números dos dois jornais. Outra sessão comum é a intitulada "Variedades", em que ambos expõem em versos ou textos suas tendências políticas, as bases de seus pensamentos, suas matrizes filosóficas. Nesta sessão do Continentino, os redatores transcreveram matérias do Carapuceiro, do Nacional, mas também citaram escritos de filósofos corroborando seu projeto político. As citações de Helvetio (Helvecio), do inglês Francis Bacon, do espanhol Geronimo V. Spanzotti ${ }^{32}$, entre outras, defendem uma boa legislação e também que o povo esclarecido é poderoso e fiel à legislação ${ }^{33}$ e que as paixões violentas "nos dilaceram" ${ }^{34}$. Estas matérias chamam atenção para a adesão ao projeto jusracionalista de matriz lockeana do grupo dos moderados do Rio de Janeiro analisados por Marcello Basile. Segundo o autor, os moderados defendiam que os direitos naturais universais dos indivíduos eram limitados pela organização da sociedade, suas instituições, mediante o pacto social fundador da sociedade e do governo ${ }^{35}$. As transcrições dos escritos de autores estrangeiros e mais antigos é um artifício muito comum da imprensa brasileira deste período, uma retórica que utilizava "a autoridade de outros para sustentarem seus argumentos" 36 .

Já O Recopilador Liberal, como o nome mesmo diz, recopilava/transcrevia matérias de jornais que compartilhavam de seu projeto político, e de seus opositores seguidas de críticas. Assim, podemos destacar alguns colaboradores para a edição deste periódico: O Paraguassú: jornal da Bahia ${ }^{37}$ (BA), A Sentinella da Liberdade do Rio de Janeiro (RJ), o Federalista de Pernambuco (PE), Tempo (RJ), Cometa (RJ), Bússola da Liberdade (PE), O Catão (RJ), Universal (MG), Jornal do Comércio (RJ), Portacollo (BA), O Observador Constitucional (SP), Nacional (RJ) e o Noticiador (RS). Outros dois jornais são citados demasiadamente pelos redatores d'O Recopilador no ano de 1833: O Inflexível e O Continentino, ambos redigidos por Joaquim José de Araújo em Porto Alegre. São 13 matérias sobre O Continentino ou O Inflexível, publicadas no jornal O Recopilador no ano de 1833. Onze matérias foram publicadas na sessão de "Correspondência" ${ }^{3}$, em que os remetentes se sentem livres para comentar e criticar os seus opositores.

No período escolhido, algumas questões sobressaem na imprensa em geral, mas sobretudo são argumentadas de formas diferentes nesses dois jornais analisados. Após a abdicação, a Regência pôs-se a reorganizar o governo, bem como colocar em prática as reformas por que lutaram durante o Primeiro Reinado. É um dado historiográfico que a união entre moderados e exaltados - partidos criados ainda no Primero Reinado em prol da saída de d. Pedro e seu governo do poder - não permaneceu nos anos regenciais, principalmente pela diferença de interesses e participação política. O Recopilador Liberal é bem claro sobre esta questão em seu número 58, quando publica uma matéria mostrando o quanto os exaltados foram prejudicados diante do rumo da revolução:

Foi ainda um erro tudo quanto se praticou com os homens do partido chamado exaltado; ligados aos princípios livres; e possuídos de um exaltamento que era todo patriótico, deveram [sic] ter sido atendidos em suas exigências, porque marchavam a par da revolução $(. . .)^{39}$.

a ser oficial maior da Secretaria do Estado dos Negócios do Império em 1849. Ver PORTO-ALEGRE, Achylles. Homens illustres do Rio Grande do Sul. Porto Alegre: Livraria Selbach, 1917. p. 184-185.

${ }^{32}$ Helvetio ou Helvecio era um filósofo francês que seguiu a linha de pensamento de John Locke; Francis Bacon era filósofo e político inglês, conhecido por dedicar-se ao conhecimento crítico e ao empirismo; e o espanhol Spanzotti pode ter sido citado pela sua posição contrária à tirania dos reis.

33 O Continentino. Porto Alegre, n. 24, 25 de abril de 1833.

34 Ibidem, n. 28, 08 de aabril de 1833.

35 BASILE, Marcello. O Império em construção... Op. Cit., p. 42 a 44.

${ }^{36}$ CARVALHO, José Murilo de. História intelectual no Brasil: a retórica como chave de leitura. Topoi, Rio de Janeiro, vol. 1, n. 1, p. 123-152, p. 137, 2000.

37 Sobre o Paraguassú, que seria um jornal baiano, nenhuma informação foi encontrada.

${ }^{38}$ Ainda há uma matéria publicada na sessão de Correspondência sobre O Continentino, no número 37 d'O Recopilador Liberal, publicado em 31 de outubro de 1832.

39 O Recopilador Liberal. Porto Alegre, n. 58, 19 de janeiro de 1833. 
O argumento utilizado por este periódico era que a revolução não foi completa, foi interrompida pelos moderados. Já $O$ Continentino distingue seus opositores em caramurus $\mathrm{x}$ anárquicos ${ }^{40}$ e sua crítica não é direcionada ao governo, mas ao contexto, acusando a política moderna de desprezar os costumes, a vida moral, em prol das leis.

\section{O contexto e os argumentos na defesa dos seus projetos: Continentino $\times$ Recopilador}

No período que delimitamos para a análise dos ditos jornais, o Rio Grande do Sul estava sob o governo de Manoel Antônio Galvão. Este assumiu como presidente em julho de 1831 e, dentre os seus primeiros ordenamentos, pedia ao escrivão da Junta da Fazenda Pública para que lhe remetesse documentos, relações e inventários. A preocupação com as receitas da província estava intrinsecamente ligada ao problema antigo da fiscalização das Alfândegas. Outras preocupações, como a organização do Exército, da Marinha, a expectativa em relação à criação da Guarda Nacional, a questão da instrução que se encontrava em estado de penúrias somavam-se à grande esperança na nova configuração política do Brasil que prometia viabilizar as administrações provinciais. Durante o seu governo, que durou até 24 de outubro de 1833, observou-se o crescimento da circulação de jornais na província. Em 1831, contabilizamos quatro jornais em circulação, enquanto, em 1833, 14 jornais circulavam na província. A abdicação e a reestruturação do governo abriram portas ao desenvolvimento da imprensa, tanto da situação, quanto opositora.

$* * * * * * * * *$

Após a abdicação do imperador e a formação de uma Regência Trina Provisória, algumas medidas imediatas foram tomadas, uma delas o decreto de "anistia para os presos, condenados ou sentenciados por crimes políticos até aquela data" ${ }^{41}$. Para Morel, por mais generoso que tenha sido esse ato, ao fim de 1831, contraditoriamente, havia cerca de 500 presos, a maioria por motivos políticos. Por mais que as primeiras medidas revelassem um enfraquecimento da monarquia, os moderados apoiaram-se no medo da revolução e no combate ao absolutismo e impuseram sua força no governo, excluindo os exaltados do poder central. Entre moderados e exaltados, a arena política foi preenchida pelos caramurus, grupo que defendia a restauração com a volta de d. Pedro I.

Sob os efeitos da ação popular nas ruas, como assinala Basile, Ceará, Pernambuco, Bahia, Minas Gerais e a Corte foram palcos de movimentos de um primeiro ciclo de revoltas do período regencial ${ }^{42}$. Foi um momento de questionamentos sobre a nova ordem das coisas e as revoltas foram a expressão popular das insatisfações. Restauradores e exaltados foram protagonistas desses movimentos que tinham diversas motivações, entre elas a forte presença de portugueses na vida econômica e política brasileira, carestia, alto custo de vida, moedas falsas, entre outras ${ }^{43}$.

As reformas começaram a ocorrer com a lei de Regência que reduziu os poderes do Executivo, dando maiores prerrogativas à Câmara, além da criação da Guarda Nacional em 18 de agosto de 1831 . Denominada “amilíciacidadã",tinhacomoobjetivogarantiro "fortalecimentodosproprietáriosesenhores locais e do poder central" 4 , sendo "uma ajuda poderosa à aniquilação de qualquer grupo, instituição ou facção contestatória das novas autoridades imperiais" 45 e à aprovação do Código de Processo Criminal em 1832, conferindo maiores poderes aos juízes de paz e alterando a estrutura jurídica brasileira. Essas mudanças não necessitaram de reformas na Constituição, entretanto, a pressão dos exaltados, o medo da restauração proposta pelo grupo dos caramurus e a esperança de que as reformas fossem feitas em "época mais tranquila" fizeram com que moderados apoiassem as reformas constitucionais propostas pelos federalistas/exaltados consubstanciadas na primeira grande reforma da Constituição:

\footnotetext{
40 O Continentino. Porto Alegre, n. 63, 10 de maio de 1832.

${ }^{41}$ MOREL, Marco. O período das... Op. Cit., p. 25.

${ }^{42}$ BASILE, Marcello. O Império brasileiro: panorama político. In: LINHARES, Maria Yedda (org.). História geral do Brasil. $10^{\text {a }}$ ed. Rio de Janeiro: Elsevier, 2016. p. 211 e 212.

${ }^{43}$ Ibidem.

44 Ibidem, p. 29.

${ }^{45}$ URICOECHEA, Fernando. O Minotauro imperial: A burocratização do Estado patrimonial brasileiro no século XIX. Rio de Janeiro: Difel, 1978.
} 
o Ato Adicional de 1834. Este sim teria, finalmente, atendido a "algumas demandas descentralizadoras, como a criação das assembleias legislativas com maior grau de autonomia e deliberação" ${ }^{\text {" }}$.

Indo de encontro a essa demanda, O Recopilador, antes do Ato Adicional, defendia não só o governo republicano, citando os EUA como referência, como exaltava o federalismo pelos versos de autoria de Paraguassú: Jornal da Bahia que, na última estrofe, dizia: "A Santa Federação nossa sorte há de mudar; há de ao ímpio dar castigo, há de ao justo premiar" ${ }^{\text {" }}$. O maior problema para o jornal exaltado era que, mesmo depois do faustoso 7 de abril, "a ineficácia pois das leis é a causa de tantos partidos que infelizmente dilaceram o vacilante Brasil". Transcrevendo o jornal Nacional, bradou aos brasileiros: "União! clama-se unanimemente; os braços se estendem, abraçam-se os Brasileiros, e só se recordam de que houve as ridículas denominações de moderados e exaltados para se rirem da pueril divisão que nos ia custando a Liberdade" ${ }^{48}$. Pede então por federação e república ${ }^{49}$.

O Continentino, por suavez, defendia o cumprimento das leis, a Constituição, o governo monárquico e o trono de d. Pedro II. Em seu primeiro número de 1833, o jornal explicava que as instituições liberais estavam se afastando do "cume" por causa das divergências de opiniões, clamando que se cumprissem "religiosamente as Leis" ${ }^{50}$. O argumento utilizado era que a Constituição não precisava mudar. Podiam até reformá-la, mas sem a destruir e seguindo as regras por ela mesma designadas. Teria seu redator, Joaquim José de Araújo, assumido este jornal para defender o projeto moderado? Vale ressaltar que o jornal O Inflexível, foi considerado jornal caramuru.

Um governista e o outro da oposição, vejamos a seguir a defesa do projeto de cada jornal, baseado nas suas reflexões particulares.

\section{O Continentino - projeto moderado?}

Considerando que a tarefa de continuar a publicar O Continentino em 1833 seria árdua e perigosa, o periódico põe-se a cumpri-la pelo bem da pátria. Esta tarefa implicaria no dever que o "homem social" tem de:

...respeitar e cumprir as Leis estabelecidas pela Sociedade a que pertence; será portanto a primeira obrigação, a que agora nos ligamos, sustentar o Governo Monárquico Representativo, e com ele o Augusto Trono de S. M. I. o Senhor Dom Pedro II; isto é a Constituição do Império, Lei Fundamental e fonte de todas as Leis; e depois disto promover a observância de todas as outras que dela se derivam; censurar todos os Empregados públicos de qualquer classe que sejam, que exatamente as não cumprirem, e em uma palavra não consentir que a arbitrariedade dos mandões (...) torne de alguma maneira a recomeçar ${ }^{51}$.

Afirma ainda nesta primeira matéria, que o sistema representativo "é o único que se conforma com a moral: ele impede a corrupção das virtudes do monarca, apoia sua fraqueza, reprime a sua força, e o mantem por todos os lados nos limites da Justiça" ${ }^{2}$. O objetivo deste número é ser um "prospecto" de abertura desta segunda fase d'O Continentino, que passou para as mãos de Joaquim José de Araújo ${ }^{53}$.

Em reflexão sobre a demanda por reformas suscitadas, principalmente pelos exaltados, $O$ Continentino considerou que havia uma "mania de reformas" porque queriam reformas em tudo, no

\footnotetext{
${ }_{46}$ MOREL, Marco. O período das... Op. Cit., p. 30.

47 Ibidem.

48 O Recopilador Liberal. Porto Alegre, n. 58, 19 de janeiro de 1833.

49 Ibidem, n. 37, 31 de outubro de 1832.

50 O Continentino. Porto Alegre, n. 1, 3 de janeiro de 1833.

${ }^{51}$ Ibidem.

52 Ibidem.

${ }^{53}$ A análise das discussões da Câmara dos Deputados e do Senado de 1828 sobre o senhor Joaquim José de Araújo indica que este não era português, mas, sim, natural da Bahia. Ele havia sido empregado da Fazenda naquela província e, em 1816, foi despachado para ser contador da Junta da Fazenda nas ilhas de Cabo Verde, atuando como escrivão deputado de 1821 a 1827 na mesma localidade. Ele pediu a sua naturalização como brasileiro, já que não residia no país há muitos anos e havia aceitado emprego de governo estrangeiro, ferindo o tit. $2^{\circ}$, art. $7^{\circ}, \$ 2^{\circ}$ da Constituição de 1824 . Após longa discussão, o pedido de naturalização foi aprovado pelas duas Câmaras.
} 
Legislativo, no Senado, moderando o Poder Moderador até "vierem totalmente a excluir do Executivo" o imperador. Quanto ao Judiciário, considerou que "já vai experimentando o Cacete político", mas também não defendeu os abusos deste poder. Nessa exposição, o redator defende as instituições, mas, principalmente, preocupa-se com a lei de 4 de outubro de 1831 que extinguiu as Juntas da Fazenda e criou tesourarias provinciais. Estas administravam e fiscalizavam as rendas públicas da província, mas, ainda assim, ficavam sob a ingerência dos presidentes de província na arrematação de contratos e despesas ${ }^{54}$. Voltaremos a este assunto mais adiante.

A crítica às reformas foi uma forma do jornal pontuar as alterações que mais incomodavam o redator, até pessoalmente. A primeira foi a extinção das Juntas da Fazenda na qual era escrivão, segundo $O$ Recopilador Liberal ${ }^{55}$. Sobre isso, $O$ Continentino afirmou que era melhor ter escolhido pessoas aptas, competentes, apoiadas em boas leis para a administração das finanças, do que criar nova repartição, pois eram despesas extraordinárias ${ }^{56}$. Outra questão para o "moderado" foi a atuação do padre Diogo Feijó como ministro da Justiça entre 1831 e 1832. Segundo Morel, Feijó "assumiu a pasta com superpoderes", estando à frente na criação da Guarda Nacional e aprovação do Código do Processo Criminal. Para o jornal, a oposição cresceu com a administração de Feijó, questionando se "Por ventura um governo composto de Cidadãos da escolha do Poder Legislativo que representa a Nação, tem de alguma maneira melhorado a nossa sorte?" ${ }^{57}$, referindo-se à eleição da Regência Trina permanente pelos deputados e senadores. O redator não podia imaginar que Feijó, dois anos depois, seria eleito regente uno.

Vinte números depois, a preocupação d'O Continentino com o processo eleitoral era manifestada com algumas instruções para os eleitores primários, explicando que os homens que seriam eleitos por eles elegeriam os deputados, portanto, deveriam ter virtudes cívicas e honra para ter consolidado o trono e a Constituição ${ }^{58}$. No número seguinte, afirma que um deputado devia satisfazer às necessidades nacionais e, em seguida, lista tais necessidades. Dentre elas estão: preservar a igualdade e liberdade civil, a propriedade, ter uma justiça esclarecida, ter um código rural e uma política forte.

A defesa do trono de d. Pedro II custou caro ao redator do Continentino que teve que se defender da acusação de restaurador. Em seu número 42, explica que o trono tinha um sucessor, explicando o porquê ele era legítimo e representava um governo a ser defendido:

...pela abdicação de seu Augusto Pai, subiu a ele o Senhor D Pedro II em menoridade, nomeando-se uma Regência permanente para durante ela governar. Se os males que física e moralmente pesavam sobre o Brasil até a época da abdicação estivessem todos circunscritos no Monarca, eles deveriam ter inteiramente cessado com este passo; porem eles continuaram a existir $(\ldots)^{59}$

Acusado, o redator procurou explicar que não era um restaurador, baseando-se na sua defesa do cumprimento da lei, de um trono legítimo - outrora contemplado por ter-nos dado a Independência - e uma Constituição liberal e representativa. Mas, talvez, o fato de Joaquim José de Araújo ser identificado como redator d'O Inflexível, não tenha colaborado para a aceitação do Continentino como periódico moderado. É interessante observar que o redator queria provar ser moderado, no entanto, ao criticar as reformas, a ampliação dos poderes do Legislativo e temer a supressão dos poderes do imperador, recaía sobre si a acusação de restaurador. Posicionamento duvidoso?

A postura dos moderados do Rio de Janeiro foi considerada "hesitante e ambígua" por Basile ${ }^{60}$

\footnotetext{
${ }^{54}$ OLIVEIRA, Carlos Eduardo França de. São Paulo em meio à remodelação da estrutura financeira provincial no início do Império: alguns apontamentos sobre as leis de 15 de novembro de 1830, 4 de outubro de 1831 e 24 de outubro de 1832. In: SIMPÓSIO NACIONAL DA ASSOCIAÇÃO DOS PROFESSORES UNIVERSITÁRIOS DE HISTÓRIA, 2011, São Paulo. Anais do XXVI Simpósio Nacional de História. São Paulo: ANPUH, 2011. p. 4.

55 O Recopilador Liberal. Porto Alegre, n. 66, 20 de fevereiro de 1833.

56 O Continentino. Porto Alegre, n. 2, 07 de janeiro de 1833.

${ }^{57}$ Ibidem, n. 3, 10 de janeiro de 1833.

58 Ibidem, n. 23, 21 de março de 1833.

${ }^{59}$ Ibidem, n. 42, 27 de maio de 1833.

${ }^{60}$ BASILE, Marcello. O Império em construção... Op. Cit., p. 59-61.
} 
no que tange ao tema das reformas na Constituição. $\mathrm{O}$ autor explica que, antes da abdicação, os moderados fluminenses se opunham às alterações no texto de 1824, enquanto que, após o 7 de abril, voltaram-se para as discussões em torno do projeto das alterações iniciadas em maio por uma comissão especial. O projeto foi apoiado pelos moderados do Rio, mas, de forma cautelosa, ainda temendo as ditas reformas e defendendo que fossem realizadas pelos meios legais ${ }^{61}$. Com discurso semelhante, $O$ Continentino,temia por reformas radicais e se pôs a instruir os seus leitores para as eleições..

O jornal criticou o governo republicano tomando como exemplo a República Oriental do Uruguai que, liderada por Frutuoso Rivera, estava, na sua opinião, entregue ao despotismo. Comparando o governo vizinho ao exemplo dos EUA, o redator explicou aos leitores a diferença desses regimes republicanos e a adequação na América do Norte:

...que esses povos, quando se constituíram, já possuíam todos os elementos necessários para seguirem essa forma, circunstância que falta aos Montevideanos e a todas as demais potências Americanas, e que só com muito tempo e à custa de muitos sacrifícios é que se pode adquirir, porque depende de uma educação própria, e privativa para isso, segundo o testemunho do celebre Montesquieu.

Portanto, o Uruguai não estava apto a ter essa forma de governo assim como o Brasil, pois não possuíam uma sociedade instruída e preparada para isso.

\section{O Recopilador Liberal - o jornal de oposição}

O jornal liberal, que se tornou oficial dos farrapos, desde o início das suas publicações defendeu o sistema federativo para o Brasil bem como o fim da monarquia. Dentre os quinze números disponíveis para pesquisa, poucas são as reflexões próprias do periódico, prevalecendo a transcrição de matérias de outros jornais. Para caracterizar o despotismo e a tirania, O Recopilador publicou matéria autoral. Em seu número 60, afirmou que o despotismo seria a vontade do monarca e a tirania estaria associada à injustiça, ou seja, o monarca, além de déspota, seria injusto. Os efeitos do despotismo, segundo o jornal, era que "Milhares de homens parece que nasceram exclusivamente para servirem a um só homem (...) sem que o ofendido tenha ao menos o jus de se queixar"62.

Contra o sistema monárquico, O Recopilador transcreve texto do Paraguassú: Jornal da Bahia que criticava os gastos inerentes a esta forma de governo. A princípio, elogia o governo dos EUA que paga um salário ao presidente sem outros custos e, em seguida, explica que no Brasil paga-se a um menor de idade e às suas irmãs. Além disso, as despesas aumentavam por conta das festividades inerentes ao sistema, como os aniversários e os casamentos: "despesas onerosíssimas só com a Casa Imperial"63.

Em matéria do jornal Nacional publicada n'O Recopilador, levantou-se a bandeira da revolução e explicou-se o que esta seria de fato. Aqui no Brasil ela foi interrompida e isso era a causa dos males que oprimiam a sociedade de então. Os dois jornais partilhavam a ideia de que a revolução nunca poderia ser fundada em princípios verdadeiramente legais, pois esses só cabiam em tempos de tranquilidade. Argumentou-se na matéria que uma revolução "não cessa tão pouco com a remoção da causa primária que a motivara”, que seria a saída de $\mathrm{d}$. Pedro, defendendo que até a Constituição deveria ter sido reformada pelo que considera "direito da revolução" ${ }^{64}$. Esse argumento era utilizado nas folhas exaltadas do Rio de Janeiro que, segundo Basile, apropriavam-se das ideias de resistência à opressão e à tirania de Locke e Rousseau ${ }^{65}$.

O Recopilador Liberal, para defender um governo democrático, tomou como referência a experiência de Atenas. Em seu número 79, dedicou-se a explicar a constituição do governo democrático dos gregos, "nossos Mestres tanto nas artes úteis, como nas agradáveis" ${ }^{66}$, os quais utilizaram o equilíbrio dos

\footnotetext{
61 Ibidem.

62 O Recopilador Liberal. Porto Alegre, n. 60, 26 de janeiro de 1833.

63 Ibidem, n. 58, 19 de janeiro de 1833.

${ }^{64}$ Idem.

65 BASILE, Marcello. O Império em construção... Op. Cit., p. 158 e 159.

${ }^{66}$ O Recopilador Liberal. Porto Alegre, n. 79, 6 de abril de 1833.
} 
poderes para eliminar da república qualquer tipo de abuso de poder e tirania, tornando-a democrática. Contra o abuso do poder, o periódico enfatizou que "devemos observar se as Autoridades competentes tomam o devido conhecimento" ${ }^{67}$. E explica seu posicionamento na arena política: entre restauradores e sectários do governo, existe um partido que presa por virtudes, liberdade e a lei.

\section{O Continentino pelos "olhos" d'O Recopilador Liberal}

Representantes de projetos políticos opostos, O Recopilador Liberal e O Continentino ocuparam a esfera pública de Porto Alegre e foram agentes na disseminação das ideias e de doutrinação política. Por mais que as reformas liberais fossem ter seu ápice no ano de $1834 \mathrm{com}$ o Ato Adicional, as questões relativas à forma como elas iriam se dar e as efetivas mudanças no texto constitucional de 1824 foram discutidas por ambos os jornais. Nesse ínterim, cabe ressaltar que os jornais analisados aqui representam uma pequena parte da imprensa no Rio Grande do Sul, representando apenas 20\% dos jornais publicados em 1832 e 14\% do total de jornais publicados em $1833^{68}$.

Analisando as correspondências publicadas n'O Recopilador Liberal sobre os jornais O Continentino e $O$ Inflexível, podemos observar as "rusgas" de natureza óbvia entre eles. Pela indisponibilidade de pesquisar $O$ Inflexível neste trabalho, incluímos as matérias direcionadas a ele n'O Recopilador pelo fato de ser editado pelo mesmo redator do Continentino e conter informações importantes a respeito do redator Joaquim José de Araújo.

Em correspondência aos redatores d'O Recopilador, "Um rio-grandense ofendido" expende longo exame sobre uma matéria publicada n'O Continentino de 17 de janeiro ${ }^{69}$ sobre o senhor José de Araújo Ribeiro. Este era embaixador brasileiro em Washington, de 1828 a 1832, veio a ser presidente da província de Minas Gerais em 1833 e, em 1834, foi eleito deputado geral pela província do Rio Grande do Sul. A correspondência publicada no jornal exaltado observa que o redator d'O Continentino faz uma "calúnia desprezível dirigida a deprimir, e tornar suspeitosa a probidade, patriotismo, e mérito do Sr. Doutor José de Araújo Ribeiro"70. Segundo o correspondente, o redator d’O Continentino não considerou o embaixador como representante da província para a próxima eleição, por ele morar nos EUA. Além disso, o correspondente aproveitou para suscitar a ideia de que o redator queria ser eleito como deputado e enfatizou que o dito Ribeiro "é merecedor do Distinto lugar de Deputado da sua Pátria"71.

No número seguinte, o assinante d'O Recopilador, Pedro José de Almeida, escreveu correspondência criticando a resposta de Joaquim José de Araújo publicada n'O Continentino afirmando que ele não era o redator d'O Inflexível. O correspondente referiu-se a Araújo como ex-escrivão da Junta da Fazenda e explorou o fato, citado anteriormente, de ter sido extinta a dita junta pelas medidas tomadas após a abdicação. Assim, o correspondente expõe sua opinião sobre Araújo:

Todos sabem perfeitamente, que o Sr. ex-escrivão Araujo estomagado, e enfurecido por não ter sido despachado Inspetor da nova Tesouraria da Província, apesar dos empenhos, e humilhações, que empregou, intentou a redação daquele periódico; $1^{\circ}$ para saciar a sua paixão e raiva contra aqueles, que o não atenderam; $2^{\circ}$ para criminar, e atacar o nosso Governo; $3^{\circ}$ para advogar a sua própria causa, engrandecer-se, e elogiar-se em falta de panegiristas; $4^{\circ}$ para censurar, e desfigurar as ordens legais emanadas do mesmo Governo; $5^{\circ}$ para ver, se inculcando-se liberal exaltado, pode iludir os Rio-Grandenses, a fim de obter, segundo a voz pública, votos para Deputados da Província ${ }^{72}$.

Em seguida, o correspondente acusa o "volúvel” Araújo de ter um “testa de ferro", o senhor Passos, para assumir a redação d’O Inflexível. Mas, na verdade, é o próprio, “pois basta ter um pouco de senso

\footnotetext{
$\overline{67 \text { Ibidem, n. 84, } 24}$ de abril de 1833.

${ }^{68}$ A partir do cruzamento de dados dos acervos sobre história da imprensa no Rio Grande do Sul e obras afins, contabilizamos nove jornais em circulação em 1832 e 14 em 1833.

69 O número 5 d'O Continentino de 17 de janeiro de 1833 não faz parte do acervo pesquisado.

70 O Recopilador Liberal. Porto Alegre, n. 59, 23 de janeiro de 1833.

${ }^{71}$ Ibidem.

72 O Recopilador Liberal. Porto Alegre, n. 60, 26 de janeiro de 1833.
} 
comum para conhecer o modo de escrever, estilo, e fraseologia do Sr. ex-Escrivão Araújo"73.

O correspondente nomeado "O Republicano de coração" escreve aos redatores d'O Recopilador sobre o redator d'O Continentino no número 64 de 13 de fevereiro. A crítica era sobre a resposta do dito redator ao correspondente do Sentinella que havia lhe questionado por tanta censura à eleição do embaixador Ribeiro como deputado. Segundo "O Republicano de coração", Araújo "teve mui pouca educação" em sua "indecorosa" resposta, e saiu em defesa do embaixador:

O Sr. Araújo Ribeiro não tem aqui agentes, que promovam cabalas em seu favor, mas se for eleito Deputado é sem dúvida alguma por esse mesmo motivo, com que o Continentino o pretende excluir da lista dos candidatos. Não posso saber se o Sr. Ribeiro consagra ideias Republicanas, mas se essa arguição é certa, não lhe causa o menor descrédito, antes pelo contrário o cobre de glória, e de honra ${ }^{74}$.

O correspondente aproveita para promover a forma de governo republicana, que O Recopilador Liberal defende. Ainda avança em dizer que "Os Brasileiros amantes da Pátria desejam quase todos, que uma REPÚBLICA FEDERAL substitua a presente forma de governo, que nos rege"75.

Joaquim José de Araújo em correspondência ao próprio Continentino, com o intuito de parecer apenas correspondente, afirma que não responderá "na forma da Lei ao Snr. = Catatuá de Quaraim=", o dito correspondente da Sentinella da Liberdade, "por estar próximo a sair para o Rio de Janeiro". Para se defender, Araújo desqualifica o jornal de "suja, e porca Sentinella", chamando-o de nojenta produção. O redator afirma que sua conduta "não padece ante os homens de bem" e pede para que os correspondentes que o acusam, como Pedro José de Almeida, para que "declarem pela mesma Imprensa a verdade"76.

Acusado pela “inflexibilidade do seu caráter" e por ter um "nobre desinteresse no serviço Civil, e Político desta Província"77, Joaquim José de Araújo respondeu a seus opositores - "este, que nos tem visto erguer intrépido o altivo colo, contra o monstruoso despotismo, que nos oprime (...), este que a olhos enxutos presencia todas as desgraças da Patria" - : "O Redator do Continentino (...) he Liberal do Coração, e não de simples parola, nem regula as suas opiniões pela ambição do mando, ou pela sede insaciável das riquezas, e só as aspira a viver honesta e modicamente com sua família (...)"78. O redator saiu de Porto Alegre para o Rio de Janeiro em maio de 1833, após publicar o último número d'O Continentino. Na edição de número 50, a penúltima, ele assina uma pequena matéria em que participa ao público que não se despediu pessoalmente de seus verdadeiros amigos e suas famílias,

...tendo de seguir para o Rio de Janeiro, d’onde voltará brevemente: Espera portanto que os mesmos se convençam da sua ingenuidade, certos de que em qualquer parte onde ele exista, e quaisquer que sejam as suas circunstâncias, o abaixo assinado estará sempre pronto a ser empregado nos objetos com que se dignarem honrá-lo.

Joaquim José de Araújo ${ }^{79}$.

O que parece uma pequena despedida será confirmada com o número seguinte, na última página d'O Continentino:

Temos finalmente concluído a nossa árdua representação no teatro do Jornalismo! Bastantemente trabalhamos para o desempenho do papel, que nele acabamos de fazer! E para que? Para merecermos repetidas palmas de uns, e incessantes pateadas dos outros!!! Assim costumam ser por via de regra as coisas deste mundo: muito barulho,

\footnotetext{
73 Idem.

${ }^{74}$ Ibidem, n. 64, 13 de fevereiro de 1833.

75 Idem.

76 O Continentino, n. 43, 30 de maio de 1833.

77 O Recopilador Liberal. Porto Alegre, n. 78, 03 de abril de 1833.

78 O Continentino, n. 45, 06 de junho de 1833.

79 Ibidem, n. 50, 24 de junho de 1833.
} 
muito desordem, para por fim revertermos ao nada donde saímos; (...) Agora iremos sem alguma distinção reunirmos ao sombrio túmulo (...)

Cumpre porém que nos últimos paroxismos da nossa existência, genuflexo, e prostrado perante a Incompreensível Majestade do Supremo Ser, fervorosamente lhe supliquemos a graça de afastar para longe do Brasil, não só todos os males (...) mas também todas as calamidades que pode atrair-lhe o desastroso futuro, que tão desapiedadamente o ameaça.

Em seguida, coloca nas mãos de d. Pedro II a "missão" de exterminar tudo que comprometa a segurança da nação, rogando que ele não "consinta que estes Povos se tornem surdos à voz da verdade".

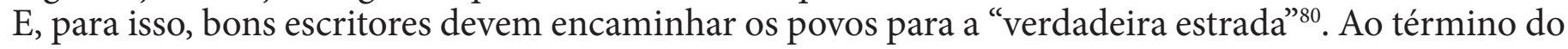
texto, o redator não assina, mas, como em uma oração, conclui com "Assim seja”. Destarte, concluiu a sua atuação na imprensa daquela província o "mal falado" redator Araújo.

Tendo apenas disponível um número d'O Recopilador Liberal no mês de junho, não encontramos nenhuma matéria a respeito do fim d'O Continentino. Araújo encerrou a publicação do jornal pedindo desculpas aos leitores pela "primeira e última vez" que alterou o dia desta publicação para quinta-feira, pois o jornal saía, impreterivelmente, às quartas e aos sábados.

\section{Conclusão}

Os posicionamentos políticos d'O Recopilador Liberal e d'O Continentino explorados a partir da análise das suas matérias tiveram como intuito desvendar aspectos da cultura impressa do Rio Grande do Sul durante o período regencial. Analisando a relação entre os dois jornais, podemos compreender que, mesmo diante de uma imprensa grandemente desenvolvida como a da capital, eles participavam ativamente do debate. As publicações demonstram o contato com as frentes políticas de outras províncias através da leitura e transcrição de jornais influentes como o Universal (MG) e a Bússola da Liberdade (PE).

O jornal $O$ Continentino, diante das acusações incessantes de ser órgão do partido restaurador, cessou sua publicação após 51 edições. O periódico, dito moderado, teve como expoente a autoria da sua redação questionada frequentemente pelo jornal exaltado O Recopilador. Joaquim José de Araújo negava ser o redator do Inflexível e do Continentino. Acastelando o trono de d. Pedro II e a Constituição, o redator teve seus interesses desvanecidos nas prévias das eleições. No início de 1833, Araújo buscou esclarecer sobre a responsabilidade dos eleitores primários, apostando na instrução como meio para mudar o Parlamento, que até aquele momento só pensava em mais reformas, segundo $O$ Continentino. No decorrer dos meses, até seu fim em maio, o jornal buscou desqualificar alguns candidatos a deputados em suas folhas, sendo acusado de uma malograda candidatura. A defesa da Constituição como lei fundamental leva-nos a acreditar que Araújo utilizou as duas publicações para persuadir o público em prol de um projeto de poder centralizado e forte, baseado na manutenção dos quatro poderes, aproximando-se muito mais do projeto caramuru do que moderado. A saída de cena tanto do redator quanto dos jornais que redigia, assemelha-se ao movimento de inflexão da imprensa caramuru da Corte no ano de 1833, em que jornais importantes foram desaparecendo subitamente ${ }^{81}$. A oposição de moderados e exaltados a um projeto restaurador, episódios de perseguições e problemas com a Justiça teriam sido os motivos para tal inflexão, segundo Marcello Basile.

O Recopilador Liberal, por sua vez, teve uma longa duração, diante dos outros periódicos, principalmente por ter sua luta consagrada com a Farroupilha. O jornal, que encerrou suas publicações em 1836 e defendia abertamente a federação para o Brasil, atuou como propagador das ideias revolucionárias na esfera pública de Porto Alegre, contribuindo para o apoio da população local à declaração de separação da província do Rio Grande do Sul do Brasil e a formação da República Rio-Grandense. Em 1833, a atuação d'O Recopilador Liberal consistiu não só na defesa do projeto político dos exaltados, como também na oposição aos jornais por ele classificados de restauradores. Por isso, parte razoável das suas publicações analisadas aqui contém críticas diretas ao Continentino e a'O Inflexível.

\footnotetext{
80 Ibidem, n. 51,27 de junho de 1833.

81 BASILE, Marcello. O Império em construção... Op. cit., p. 369.
} 
A folha exaltada e a caramuru - que se dizia moderada - foram agentes importantes na divulgação de ideias naquela província, visto que o desenvolvimento da imprensa local era recente. Sendo assim, utilizamos a imprensa como fonte para compreender a dinâmica política local, os debates travados entre os dois jornais escolhidos, tendo como finalidade, contribuir para as análises sobre o período regencial.

\section{Referências bibliográficas}

\section{Fontes primárias}

O Continentino, Biblioteca Nacional.

O Recopilador Liberal, Biblioteca Nacional.

\section{Fontes secundárias}

ALVES, Francisco das Neves. O periodismo gaúcho no século XIX: breves impressões históricas. In: Biblos, Rio Grande, vol. 23, n. 2, p. 137-166, 2009.

BARRETO, Abeillard. Primórdios da imprensa no Rio Grande do Sul. Comissão Executiva do Sesquicentenário da Revolução Farroupilha. Porto Alegre, 1986;

BASILE, Marcello. O Império em construção: projetos de Brasil e ação política na Corte Regencial. Tese (Doutorado), I.F.C.S., Universidade Federal do Rio de Janeiro, Rio de Janeiro, 2004.

Inventário analítico da imprensa periódica do Rio de Janeiro na Regência: perfil dos jornais e dados estatísticos. In: CARVALHO, José Murilo de; NEVES, Lúcia Maria Bastos P. (org.). Dimensões e fronteiras do Estado Brasileiro nos Oitocentos. Rio de Janeiro: Eduerj, 2014.

O Império brasileiro: panorama político. In: LINHARES, Maria Yedda. (org.). Historia geral do Brasil. 10a ed. Rio de Janeiro: Elsevier, 2016.

CARVALHO, José Murilo de; BASTOS, Lúcia; BASILE, Marcello (org.). Às armas, cidadãos! Panfletos manuscritos da Independência do Brasil (1820-1823). São Paulo: Companhia das Letras; Belo Horizonte: Editora UFMG, 2012

História intelectual no Brasil: a retórica como chave de leitura. Topoi, Rio de Janeiro, vol. 1, n. 1, p. 123-152, 2000.

CARVALHO, Fernanda Costa; MOREL, Marco; PIRES, Myriam. História da imprensa no Brasil Império: abordagem metodológica e síntese histórica (1822-1849). Trabalho de iniciação científica, Universidade do Estado do Rio de Janeiro, Rio de Janeiro, 2004.

COLLOR, Lindolfo. Garibaldi e a Guerra dos Farrapos. Brasília: Senado Federal, Conselho Editorial, 2016.

FONSECA, Silvia Carla Pereira de Brito; CORREAA, Maria Letícia (org.). 200 anos de imprensa no Brasil. Rio de Janeiro: Contra Capa, 2009.

HABERMAS, Jurgen, Mudança estrutural da esfera pública: investigações quanto a uma categoria da sociedade burguesa. Rio de Janeiro: Tempo Brasileiro,1984.

JUNG, Roberto Rossi. A gaúcha Maria Josefa, primeira jornalista brasileira. Porto Alegre: Martins Livreiro, 2004;

LUCA, Tania Regina de. História dos, nos e por meio dos periódicos. 2a ed. In: PINSKY, Carla (org.). Fontes históricas. São Paulo: Contexto, 2006.

MOREL, Marco. As transformações dos espaços públicos: imprensa, atores políticos e sociabilidades na Cidade Imperial (1820-1840). São Paulo: Hucitec, 2005.

$$
\text { O período das regências (1831-1840). Rio de Janeiro: Editora Jorge Zahar, } 2003 .
$$

NEVES, Lúcia Maria Bastos Pereira das. Corcundas e constitucionais: a cultura política da Independência (1820-1822). Rio de Janeiro: Revan / Faperj, 2003.

OLIVEIRA, Carlos Eduardo França de. São Paulo em meio à remodelação da estrutura financeira provincial no início do Império: alguns apontamentos sobre as leis de 15 de novembro de 1830, 4 de outubro de 1831 e 24 de outubro de 1832. In: SIMPÓSIO NACIONAL DE HISTÓRIA, 2011, São Paulo. Anais do XXVI Simpósio Nacional de História. ANPUH. São Paulo: Associação Nacional de História, 2011.

PORTO-ALEGRE, Achylles, Homens illustres do Rio Grande do Sul. Porto Alegre: Livraria Selbach, 1917.

REVERBEL, Carlos. Evolução da imprensa rio-grandense (1827-1845). In: Enciclopédia Rio-Grandense. Porto Alegre, 1956. 
RÜDIGER, Francisco. Tendências do jornalismo. Porto Alegre, Edipucrs, 2002.

SCHMITT, Ânderson Marcelo. "Não admito escusa alguma": confiscos e recrutamentos na guerra civil riograndense (1835-1845). Dissertação (Mestrado). Universidade de Passo Fundo, 2014.

SODRÉ, Nelson Werneck. A história da imprensa no Brasil. Rio de Janeiro: Mauad, 1999.

STRELOW, Aline. Primórdios da imprensa literária no Rio Grande do Sul. A história do jornal O Guayba. UFOP, 2013.

URICOECHEA, Fernando. O Minotauro imperial: A burocratização do Estado patrimonial brasileiro no século XIX. Rio de Janeiro: Difel, 1978.

Recebido em: 20/03/2018 - Aprovado em: 01/10/2018 